\title{
Calcium Phosphate Coatings by Sol-Gel on Acrylonitrile-butadiene-styrene Substrate
}

\author{
Lucimara C. Bandeira, ${ }^{a}$ Beatriz M. de Campos, ${ }^{a}$ Katia J. Ciuffi, ${ }^{a}$ Eduardo J. Nassar, ${ }^{*, a}$ \\ Jorge V. L. Silva, ${ }^{b}$ Marcelo F. Oliveira ${ }^{b}$ and Izaque A. Maia ${ }^{b}$ \\ ${ }^{a}$ Universidade de Franca, Av. Dr. Armando Salles Oliveira, 201 Pq. Universitário, \\ 14404-600 Franca-SP, Brazil \\ ${ }^{b}$ Centro da Tecnologia da Informação Renato Archer (CTI), Rod. Dom Pedro I, Km 143.6, \\ 13069-901 Campinas-SP, Brazil
}

\begin{abstract}
Additive manufacture is an effective technology to produce complex macrostructures from polymers. Sol-gel is a chemical process that affords multifunctional materials by functionalization of different substrates. This work reports on the use of acrylonitrile-butadiene-styrene polymer (ABS) as starting material to obtain a substrate by additive manufacture. Coating of ABS by the sol-gel methodology generated a multifunctional material. Sols with and without phosphate ions were prepared from silicon and calcium alkoxide. Based on X-ray diffraction patterns, a calcium phosphate crystalline structure emerged on ABS after contact of the substrate with simulated body fluid. Infrared analysis revealed that the peaks of the functionalized substrate shifted, indicating that ABS interacted with the sol-gel coating. According to thermal analysis, the maximum decomposition temperature of the coated samples was $20^{\circ} \mathrm{C}$ higher as compared to non-coated ABS. Sol-gel and additive manufacture are important technologies to produce materials with applications in biological medium.
\end{abstract}

Keywords: dip-coating, sol-gel, biomaterials

\section{Introduction}

Additive manufacture (AM, also known as rapid prototyping) assembles materials in the powder, filament, liquid, or slide form. The materials consist of successively stacked thin layers, resulting in a three-dimensional structure.

AM uses computer-aided design (CAD) software to build a mould for the scaffold. The mould displays a branching network of shafts that will define the microchannels in the scaffold. ${ }^{1-5}$ The fusion deposition model (FDM) technique helps to structure the acrylonitrilebutadiene-styrene polymer (ABS), a mobile extruder head deposits layers of molten material. The layer-by-layer building approach produces highly complex structures that would be impossible to achieve with technologies based on material subtraction, the most frequently employed procedure nowadays. AM has important applications in several areas, including the aircraft and automobile industries, telecommunications, and medicine. ${ }^{6-8}$

The sol-gel route is a chemical process that involves formation of a sol, namely a colloidal suspension of

*e-mail: eduardo.nassar@unifran.edu.br particles or molecules with liquid character and measuring between 1 and $1000 \mathrm{~nm}$. The sol later goes through a gel phase, which consists of a colloidal system with solid character. In the gel phase, the molecules form a dispersed, continuous, branched, and interpenetrated structure in a system that is usually liquid. After solvent evaporation, the gel phase becomes a solid material that can be either a xerogel, if the solvent is removed by simple evaporation, or an aerogel, if the solvent is removed above its critical temperature and pressure. ${ }^{9-12}$

The sol-gel process is widely employed to prepare glasses and oxides and to modify surfaces. Sol-gel encompasses hydrolysis and condensation of metal alkoxides or semi-metallic precursors under mild conditions, to generate a polymer network. ${ }^{13-19}$ Alkoxides can form homogeneous sols in various solvents and in the presence of other alkoxides or metal derivatives, to produce homogeneous materials at the molecular level. The sol-gel process uses silicon alkoxides $\mathrm{Si}(\mathrm{OR})_{\mathrm{n}}$, where $\mathrm{R}$ is an organic group $\left(-\mathrm{CH}_{3},-\mathrm{C}_{2} \mathrm{H}_{5}\right.$, etc.). In contact with water, $\mathrm{Si}(\mathrm{OR})_{\mathrm{n}}$ undergo hydrolysis, to generate silanol groups $(\mathrm{Si}-\mathrm{OH})$. Condensation between $\mathrm{Si}-\mathrm{OH}$ groups, a pH-dependent process, affords $\mathrm{Si}-\mathrm{O}-\mathrm{Si}$ bonds. 
Acid catalysts produce dense networks, whereas alkali catalysts give porous xerogels. ${ }^{20}$ The sol-gel technology is an excellent strategy to coat substrates with complex geometry under mild temperatures and low pressure; it employs liquid precursors. ${ }^{20-24}$

Here, we studied how the properties of the ABS substrate obtained by AM changed after we coated the ABS polymer with silicon alkoxide and calcium ion by the sol-gel methodology. Sols with and without phosphate ion were prepared before the sol-gel process. In vitro tests were performed in simulated body fluid solution. The ABS surface was coated by the dip-coating technique. Scanning electron microscopy (SEM), thermal analysis, X-ray diffraction and infrared spectroscopy aided the analyses of the materials.

\section{Experimental}

\section{Sample preparation}

Sols were prepared by reaction between tetraethylortosilicate (TEOS) and calcium alkoxide in ethanol, under stirring. Two sols were prepared: one contained phosphate ions ( $\mathrm{Si}-\mathrm{Ca}-\mathrm{P})$, but the other did not (Si-Ca). After $30 \mathrm{~min}$, the basic catalyst, namely saturated $\mathrm{NH}_{3}$ ethanolic solution, was added. The ABS substrates were dipped into the resulting solution for $20 \mathrm{~min}$, washed in distilled water, and dried at $50{ }^{\circ} \mathrm{C}$ for 1 day.

The sols were deposited on ABS by dip-coating, as described in the literature. ${ }^{13,21,25}$ Dip-coating consisted in immersing the substrate directly into the prepared sols.

Simulated body fluid (SBF) was prepared in aqueous solution. The reagent, $\mathrm{NaCl}, \mathrm{NaHCO}_{3}, \mathrm{KCl}, \mathrm{Na}_{2} \mathrm{HPO}_{4} \cdot 2 \mathrm{H}_{2} \mathrm{O}$, $\mathrm{MgCl}_{2} \cdot 6 \mathrm{H}_{2} \mathrm{O}, \mathrm{HCl}, \mathrm{CaCl}_{2} \cdot \mathrm{H}_{2} \mathrm{O}, \mathrm{NaSO}_{4}$, and $\mathrm{NH}_{2} \mathrm{C}\left(\mathrm{CH}_{2} \mathrm{OH}\right)$ were added to water, under stirring. ${ }^{26}$ The final $\mathrm{pH}$ was 7.43. The samples were immersed into SBF for 15 days, to crystallize the phosphates. The SBF treatment was performed in static condition. Finally, the samples were dried at $50{ }^{\circ} \mathrm{C}$ and characterized.

The ABS substrates used in this work consisted of rectangular slides measuring $75 \times 25 \times 1 \mathrm{~mm}$, built in an FDM equipment located at the Research Center of the Brazilian government (CTI).

\section{Thermal analysis (TG/DTA/DSC)}

Thermogravimetry (TG), differential thermal analysis (DTA), differential scanning calorimetry (DSC) were carried out in a Thermal Analyzer (TA Instruments-SDT Q600, Simultaneous DTA-TG), under nitrogen atmosphere, at a heating rate of $20^{\circ} \mathrm{C} \mathrm{min}^{-1}$, from 25 to $650{ }^{\circ} \mathrm{C}$.

\section{Scanning electron microscopy}

A JEOL JSM-T330A microscope was used for SEM analysis. A sputtering method was used to coat the samples.

Infrared spectroscopy (FTIR-ATR)

The Fourier transform infrared (FTIR) absorption spectra were obtained on a Mattson 7000 spectrometer, operating in the attenuated total reflectance (ATR) mode.

\section{X-Ray diffraction (XRD)}

The X-ray diffractograms were registered on a Rigaku XD MAX diffractometer operating at $40 \mathrm{kV}$ and $30 \mathrm{~mA}$ $(1200 \mathrm{~W}) ; \mathrm{CuK} \alpha$ radiation was employed. The angle $2 \theta$ varied from 5 to $50^{\circ}$. All the analyses were undertaken at a scan rate of $2^{\circ}$ per minute.

\section{Results and Discussion}

The coatings adhered well to the substrates and covered all the materials, designated AcP and AsP for the samples with and without phosphate ion, respectively.

\section{Scanning electron microscope}

Figure 1 shows the SEM micrographs recorded for $\mathrm{AcP}$ and AsP, which confirmed coating of the materials. A previous work ${ }^{24}$ found that the ABS surface was rough and microporous. Here, examination of the surface and of the interface of the coated materials by SEM detected a non-homogeneous coating on the surface of the ABS substrate (Figures 1a-1d). The coating extended across the substrate evenly, with approximately $5 \mu \mathrm{m}$ thick, and integrated well into ABS (Figure 1a).

\section{Thermal analysis (TG/DTA/DSC)}

Figure 2 depicts the thermal analyses of the non-coated ABS substrate and of the samples AcP and AsP.

The initial decomposition temperature was practically the same for the three samples, around $365^{\circ} \mathrm{C}$, indicating that the coating did not affect this parameter. The maximum decomposition temperature of the coated samples was $20{ }^{\circ} \mathrm{C}$ higher as compared to uncoated ABS.

Based on the DTA and DSC curves, ABS and the coated samples (AcP and AsP) underwent an endothermic sample decomposition process at 415 and $435{ }^{\circ} \mathrm{C}$, respectively. Glass transition ${ }^{27}$ occurred at 113 and $117^{\circ} \mathrm{C}$ for ABS and the coated samples, respectively. ABS melted at $175^{\circ} \mathrm{C}, 28$ 

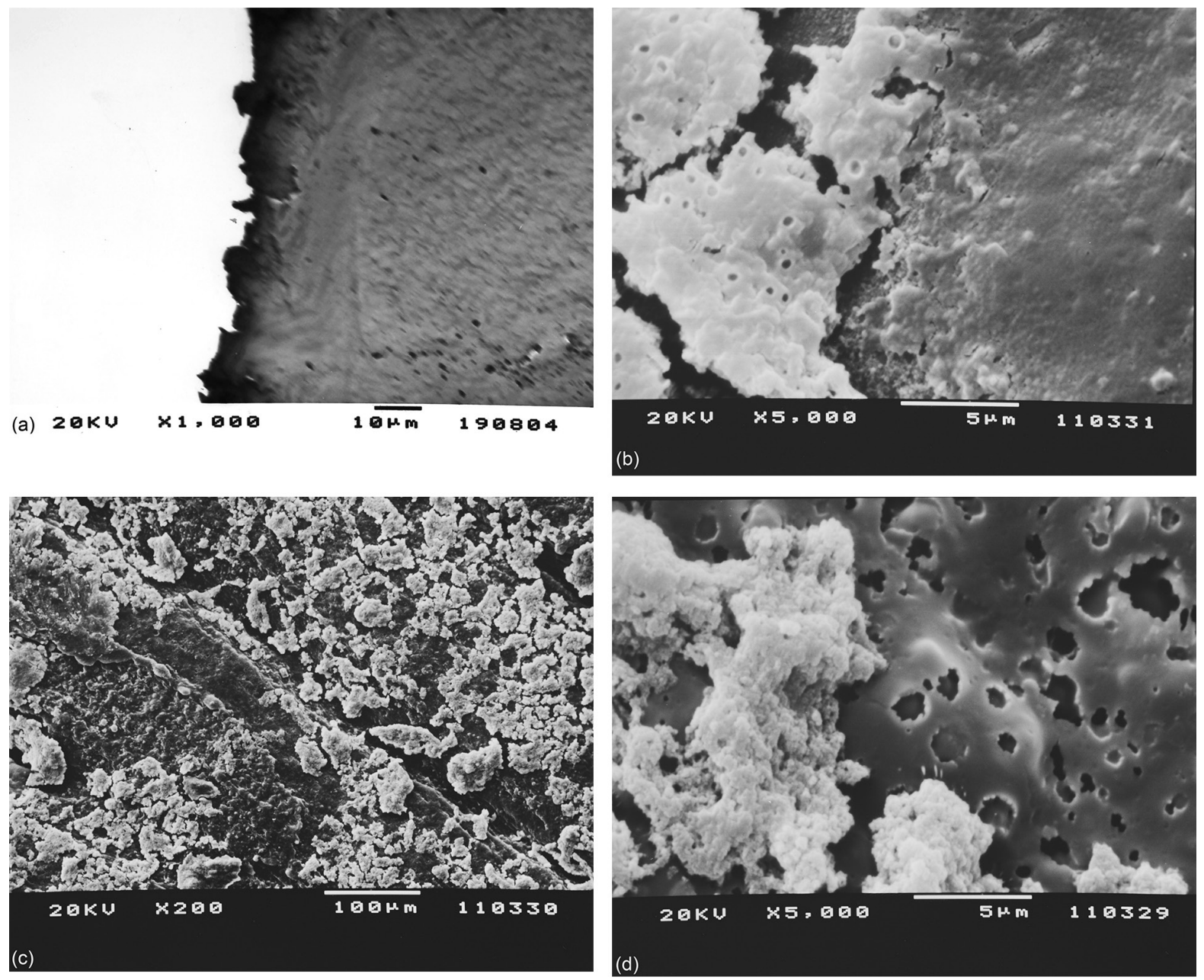

Figure 1. SEM micrographs of the surface of the ABS substrate. (a) Interface of the sample AcP; (b) surface of the sample AcP; and (c and d) surface of the sample AsP.

but no sign of ABS melting emerged at this temperature for the coated samples. In fact, AcP and AsP had higher melting points, 198 and $204{ }^{\circ} \mathrm{C}$, respectively.

Figure 3 presents the thermal analysis of the samples AcP and AsP after contact with SBF for 15 days, respectively.

After 15 days in SBF, the melting point of sample AcP increased $6{ }^{\circ} \mathrm{C}$ as compared to AcP before contact with SBF (Figure 3a). Therefore, the coating did not dissolve in SBF, and contact between AcP and SBF must have modified the sample surface. The maximum decomposition temperature of AcP also increased after contact with SBF. The same observations were also true for AsP placed in SBF for 15 days (Figure $3 b$ ).

\section{X-Ray diffraction}

Figure 4 illustrates the XRD patterns of the ABS substrate and the samples AcP and AsP.

The XRD patterns of the three samples displayed broad peaks between 10 and $30^{\circ}$, characteristic of amorphous materials. The coated samples did not present peaks characteristics of crystalline materials, showing that the thickness of the coating film was small.

Figure 5 contains the XRD patterns of samples AcP and AsP before and after contact with SBF for 15 days.

New peaks emerged in the XRD pattern of AcP and AsP after contact with SBF, which evidenced initial crystallization: peaks appeared at $2 \theta=10.6,21.6,31.6$, and $45.2^{\circ}$ for AcP, whereas only two peaks emerged for AsP, at $2 \theta=31.6$ and $44.9^{\circ}$. The latter peaks corresponded to a mixture of calcium phosphate silicates (JCPDS 21-0157; 11-0676). These alterations in the XRD pattern of the coated samples after 15 days in SBF showed that the coating interacted with SBF to form calcium phosphate, the main component of hydroxyapatite.

\section{Infrared spectroscopy}

Figure 6 corresponds to the FTIR-ATR spectra of ABS and the samples AcP and AsP. 
(a)

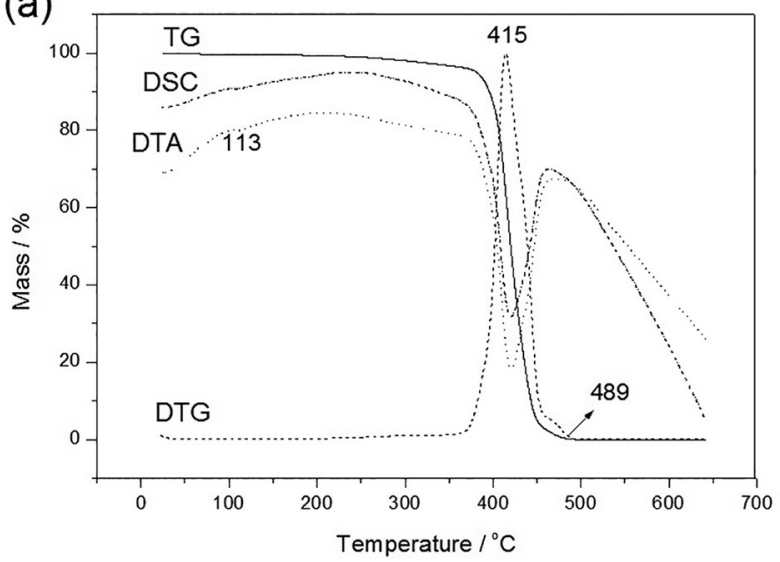

(b)

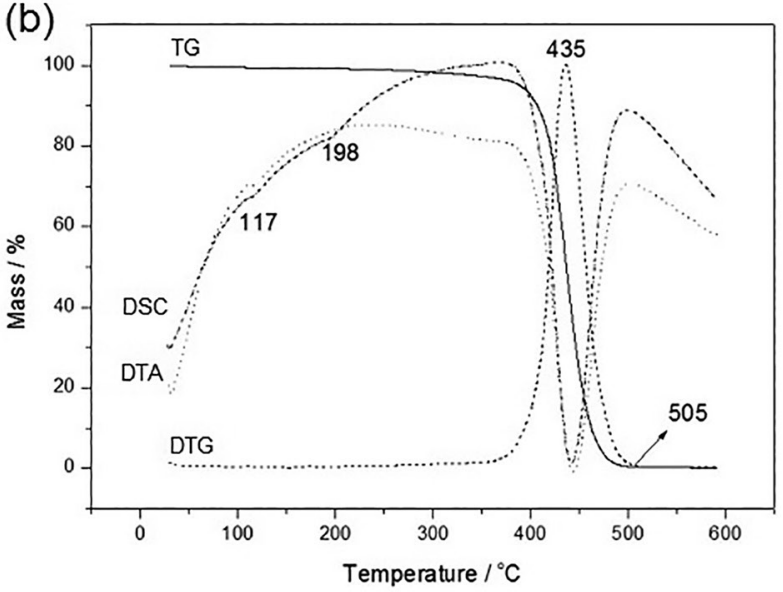

(c)

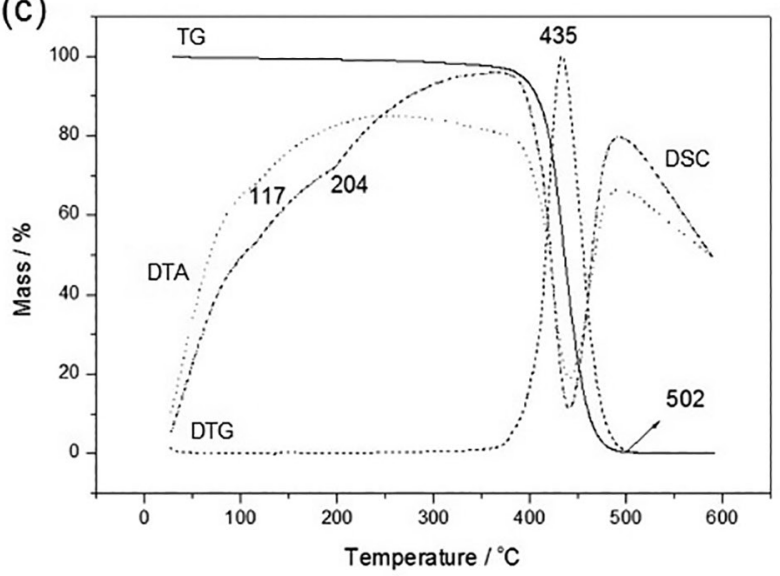

Figure 2. Thermal analyses of the samples (a) ABS; (b) AcP; and (c) AsP.

The typical vibration modes of the acrylonitrile, styrene, and butadiene groups of the ABS polymer appeared in the spectra of the ABS substrate at 2356, 1592, and $955 \mathrm{~cm}^{-1}$, respectively. ${ }^{29}$ After coating, these bands shifted to 2365 , 1598 , and $960 \mathrm{~cm}^{-1}$ for AcP and to 2365, 1603, and $966 \mathrm{~cm}^{-1}$ for AsP, respectively (see Table 1). Interaction between the functional groups on $\mathrm{ABS}$ and the sol-gel coating accounted for the shifts. In particular, the shift from $2359 \mathrm{~cm}^{-1}$ in ABS to $2365 \mathrm{~cm}^{-1}$ in AcP and AsP originated from interaction
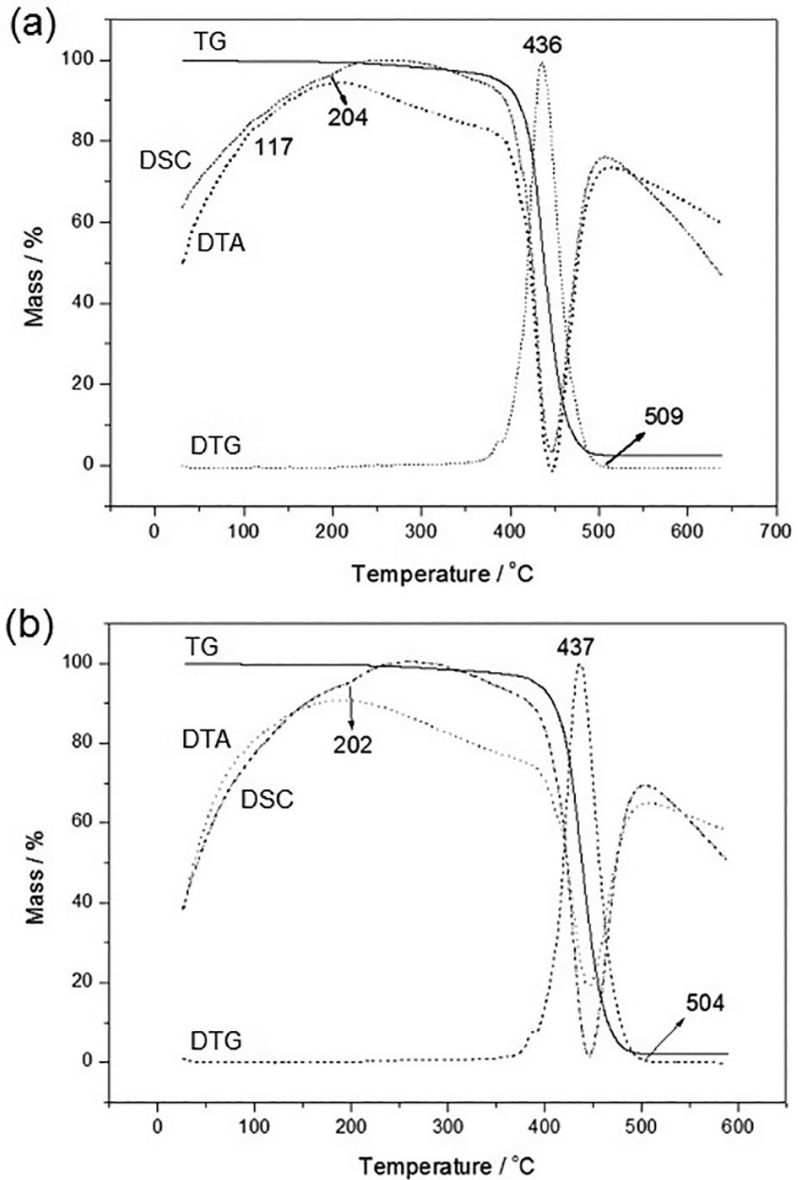

Figure 3. Thermal analyses of the samples (a) AcP and (b) AsP after 15 days in $\mathrm{SBF}$

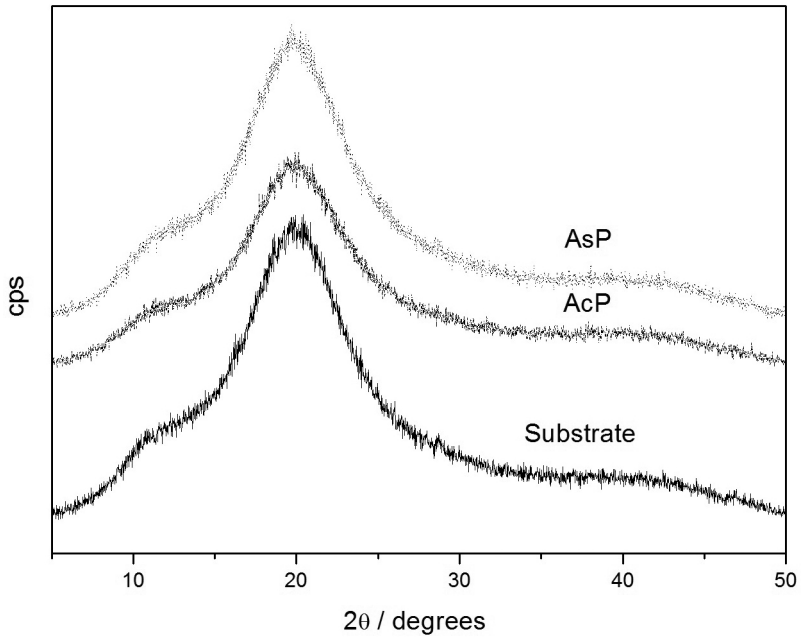

Figure 4. XRD analysis of the ABS substrate and of the samples AcP and AsP

between the nitrile group on $\mathrm{ABS}$ and the coating. The peaks ascribed to $\mathrm{C}=\mathrm{C}$ appeared at 1592 and $955 \mathrm{~cm}^{-1}$ for $\mathrm{ABS}$, 1598 and $960 \mathrm{~cm}^{-1}$ for AcP, and 1603 and $966 \mathrm{~cm}^{-1}$ for AsP

Table 2 describes the main vibration modes observed for the samples and their attribution. 

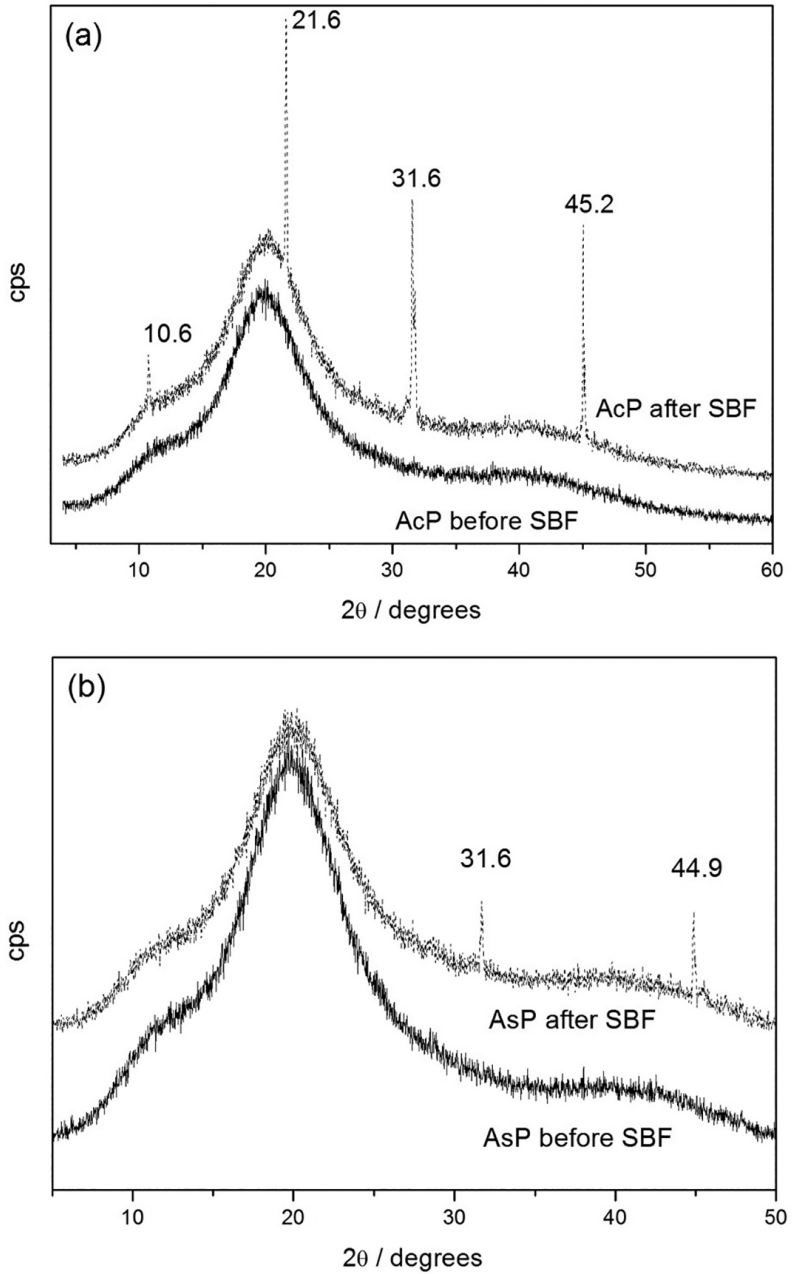

Figure 5. XRD of the samples (a) AcP and (b) AsP before and after 15 days in SBF.

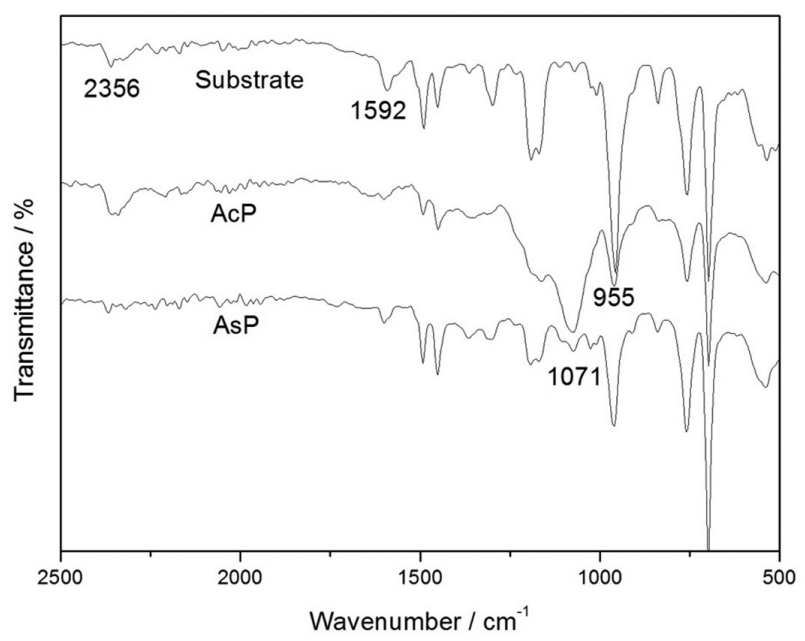

Figure 6. FTIR-ATR reflectance spectra of ABS, AcP, and AsP.

Compared to the FTIR-ATR spectrum of ABS, new peaks arose in the spectra of AcP and AsP at 1077 and $460 \mathrm{~cm}^{-1}$, ascribed to $\mathrm{Si}-\mathrm{O}-\mathrm{Si}$ vibrations. These peaks confirmed that the coating was present on the ABS substrate.
Table 1. Bands in the FTIR-ATR spectra of the ABS substrate before and after coating

\begin{tabular}{lccc}
\hline \multirow{2}{*}{ Sample } & \multicolumn{3}{c}{ Wavenumber $/ \mathrm{cm}^{-1}$} \\
\cline { 2 - 4 } & Acrylonitrile & Styrene & Butadiene \\
\hline ABS substrate & 2359 & 1592 & 955 \\
AcP & 2365 & 1598 & 960 \\
AsP & 2365 & 1603 & 966 \\
\hline
\end{tabular}

Table 2. Attribution of the vibration modes emerging in the FTIR-ATR spectra of ABS, AcP, and AsP

\begin{tabular}{lc}
\hline Wavenumber $/ \mathrm{cm}^{-1}$ & Assignment \\
\hline 2922 & $\mathrm{C}-\mathrm{H}$ acyclic \\
2350 & $\mathrm{~N} \equiv \mathrm{C}$ \\
1589 & $\mathrm{C}=\mathrm{C}$ conjugate \\
1492 & $\mathrm{C}-\mathrm{H}$ \\
1450 & $\mathrm{CH}_{2} \mathrm{CN}$ \\
$1187-1166$ & $\mathrm{C}-\mathrm{H}$ \\
$955-839$ & $\mathrm{C}=\mathrm{C}$ \\
$757-696$ & aromatic \\
539 & nitrile \\
$1077-460$ & Si-O-Si \\
\hline
\end{tabular}

Figure 7 contains the FTIR-ATR spectra of the ABS substrate before coating and samples AcP and AsP after 15 days into SBF.

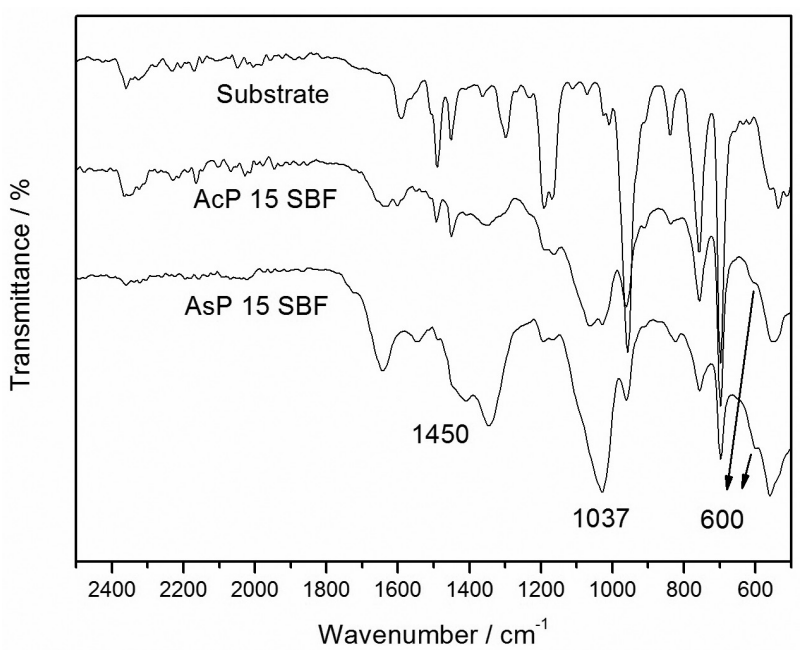

Figure 7. FTIR-ATR reflectance spectra of the ABS substrate and samples AcP and AsP after 15 days in SBF.

The FTIR-ATR of AcP and AsP after contact with SBF still presented peaks at 1037 and $465 \mathrm{~cm}^{-1}$, typical 
of $\mathrm{Si}-\mathrm{O}-\mathrm{Si}$ vibrations, indicating that the silicate coating did not dissolve in SBF. New peaks appeared at 3360 and $1653 \mathrm{~cm}^{-1}$, due to water vibrations, and at 600 and $550 \mathrm{~cm}^{-1}$, assigned to $\mathrm{P}-\mathrm{O}$ vibration. ${ }^{30}$ The latter peaks corroborated the X-ray analysis data and indicated formation of calcium phosphate silicate. The FTIR-ATR spectrum of the sample AsP after contact with SBF displayed peaks characteristic of hydroxyapatite at 1451,1408 , and $874 \mathrm{~cm}^{-1} \cdot{ }^{30}$

\section{Conclusion}

The ABS polymer obtained by additive manufacture was coated with silicate by the sol-gel process. The sol-gel coatings, prepared at room temperature, exhibited good features for application in biomaterials. Crystallization of these coatings after contact with SBF indicated that they did not dissolve in SBF, but interacted strongly with this solution. The XRD results suggested that a phosphate phase emerged in the coating layer after contact between the sample and SBF. These results open the possibility of producing hydroxyapaptite for use as bone replacement, for example, the polymer employed here presents good mechanical strength, and the FDM technique can generate several 3D structures from this polymer. The sol-gel methodology can be an alternative strategy to produce coatings over polymeric substrates structured by additive manufacture. The sol-gel process can be conducted at room temperature and is an inexpensive, environmentally friendly technique.

\section{Acknowledgments}

The authors acknowledge CNPq and CAPES (Brazilian research funding agencies) for support of this work. L. C. B. (grant 2008/09876-8) and B. M. C. (grant 2012/22927-6) thank the São Paulo Research Foundation (FAPESP, Brazil) for scholarships.

\section{References}

1. Sachlos, E.; Wahl, D. A.; Triffitt, J. T.; Czernuszka, J. T.; Acta Biomater. 2009, 4, 1322.

2. Liulan, L.; Qingxi, H.; Xianxu, H.; Gaochun, H.; J. Rare Earths 2007, 25, 379.

3. Sachlos, E.; Reis, N.; Ainsley, C.; Derby, B.; Czernuszka, J. T.; Biomaterials 2003, 24, 1487.

4. Li, J.; Habibovic, P.; Yuan, H.; van den Doel, M.; Wilson, C. E.; de Wijn, J. R.; van Blitterswijk, C. A.; de Groot, K.; Biomaterials 2007, 28, 4209.

5. Hollander, D. A.; von Walter, M.; Wirtz, T.; Sellei, R.; SchmidtRohlfing, B.; Paar, O.; Erli, H.; Biomaterials 2006, 27, 955.
6. Lee, B. H.; Abdullah, J.; Khan, Z. A.; J. Mater. Process. Technol. 2005, 169, 54.

7. Mostafa, N.; Syed, H. M.; Igor, S.; Andrew, G.; Tsinghua Sci. Technol. 2009, 14, 29.

8. Galantucci, L. M.; Lavecchia, F.; Percoco, G.; CIRP Ann. 2008, $57,243$.

9. Hench, L. L.; Sol-Gel Silica; Noyes Publications: Amsterdam, Netherlands, 1998.

10. Wright, J. D.; Sommerdijk, N. A. J. M.; Sol-Gel Materials Chemistry and Applications, vol. 4; Taylor \& Francis: Amsterdam, Netherlands, 2001.

11. Brinker, C. J.; Scherer, G. W.; Sol-Gel Science, The Physics and Chemistry of Sol-Gel Processing; Academic Press: San Diego, USA, 1990.

12. Aegerter, M. A.; Menning, M.; Sol-Gel Technologies for Glass Producers and Users; Kluwer Academic Publishers: Boston, USA, 2004.

13. Nassar, E. J.; Ciuffi, K. J.; Gonçalves, R. R.; Messaddeq, Y.; Ribeiro, S. J. L.; Quim. Nova 2003, 26, 674.

14. Rokesh, K.; Pandikumar, A.; Mohan, S. C.; Jothivenkatachalam, K; J. Alloys Compd. 2016, 680, 633.

15. Álvarez, D.; Collazo, A.; Nóvoa, X. R.; Pérez, C.; Prog. Org. Coat. 2016, 96, 3.

16. Azevedo, C. B.; Batista, T. M.; de Faria, E. H.; Rocha, L. A.; Ciuffi, K. J.; Nassar, E. J.; J. Fluoresc. 2015, 25, 433.

17. Xin, Z.; Lei, M.; Jian-gang, W.; Hui-min, Z.; Optik 2016, 127, 2780.

18. Shen, Y.; Yan, X.; Zhao, S.; Chen, X.; Wei, D.; Gao, S.; Han, C.; Meng, D.; Sens. Actuators, B 2016, 230, 667.

19. Zhao, Y.; Xu, H.; Zhang, X.; Zhu, G.; Yan, D.; J. Eur. Ceram. Soc. 2015, 35, 3761.

20. Coradin, T.; Boissiere, M.; Livage, J.; Curr. Med. Chem. 2006, $13,99$.

21. Bagheri, H.; Piri-Moghadam, H.; Ahdi, T.; Anal. Chim. Acta 2012, 742, 45.

22. Owens, G. J.; Singh, R. K.; Foroutan, F.; Alqaysi, M.; Han, C.-M.; Mahapatra, C.; Kim, H.-W.; Knowles, J. C.; Prog. Mater. Sci. 2016, 77, 1.

23. Singh, L. P.; Bhattacharyya, S. K.; Kumar, R.; Mishra, G.; Sharma, U.; Singh, G.; Ahalawat, S.; Adv. Colloid Interface Sci. 2014, 214, 17.

24. de Souza, E. A.; Azevedo, C. B.; Rocha, L. A.; de Faria, E. H.; Calefi, P. S.; Ciuffi, K. J.; Nassar, E. J.; Silva, J. V. L.; Oliveira, M. F.; Maia, I. A.; J. Mater. Res. 2012, 27, 2088.

25. Bandeira, L. C.; de Campos, B. M.; de Faria, E. H.; Ciuffi, K. J.; Calefi, P. S.; Nassar, E. J.; Silva, J. V. L.; Oliveira, M. F.; Maia, I. A.; J. Therm. Anal. Calorim. 2009, 97, 67.

26. Kokubo, T.; Kushitani, H.; Sakka, S.; Kitsugi, T.; Yamamuro, T.; J. Biomed. Mater. Res. 1990, 24, 721.

27. Martins, J. N.; Klohn, T. G.; Bianchi, O.; Fiorio, R.; Freire, E.; Polym. Bull. 2010, 64, 497. 
28. Bandeira, L. C.; Ciuffi, K. J.; Calefi, P. S.; Nassar, E. J.; Silva, J. V. L.; Oliveira, M. F.; Maia, I. A.; Salvado, I. M.; Fernandes, M. H. V.; J. Braz. Chem. Soc. 2012, 23, 810.

29. Boricha, A. G.; Murthy, Z. V. P.; J. Membr. Sci. 2009, 339, 239.
30. Peter, M.; Binudal, N. S.; Soumya, S.; Nair, S. V.; Furuike, T.; Tamura, H.; Kumar, R. J.; Carbohydr. Polym. 2010, 79, 284.

Submitted: June 16, 2016

Published online: August 24, 2016

FAPESP has sponsored the publication of this article. 